\title{
Superrealistas. De la contribución de los rayos-x a la visión y presentación de la realidad en el arte de comienzos del siglo $X X$
}

\author{
Ana Lamata Manuel \\ Universidad Complutense de Madrid
}

\begin{abstract}
RESUMEN
Algunas consideraciones acerca de las resonancias del descubrimiento de los rayos-x en la práctica artística europea a comienzos del siglo XX, a partir de las cuales se enuncia la tesis de que el superrealismo habría sido el único ismo de la época.
\end{abstract}

Palabras clave: Superrealismo; rayos-x; visión; Guillaume Apollinaire; Pablo Picasso; Marcel Duchamp; Giorgio de Chirico; Francis Picabia; futuristas; Loïe Fuller.

Superrealists. On the contribution of $x$-rays to the vision and presentation of reality in the art of the beginning of $20^{\text {th }}$ century

\begin{abstract}
Some reflexions about the resonances of the discovery of the x-rays in the european artistic practice in the early twentieth century, from which we set forth the thesis that superrealism would have been the ism of the epoch.
\end{abstract}

Keywords: Superrealism; x-rays; vision; Guillaume Apollinaire; Pablo Picasso; Marcel Duchamp; Giorgio de Chirico; Francis Picabia; futuristas; Loïe Fuller.

Guillaume Apollinaire fue quien enunció la idea de superrealismo hacia la cual han ido confluyendo las incursiones emprendidas con ocasión de observar las resonancias del descubrimiento de los rayos-x en la práctica artística de sus contemporáneos. El superrealismo planteado por Apollinaire fue el espíritu nuevo de la época: l'air du temps. Una actitud que no era otra cosa que un profundo realismo que había dejado de ser el sistema o escuela que había venido siendo. Un realismo desplegado en profundidad y no en altura como el surrealismo bretoniano ${ }^{1}$. Un rea-

1 En enero de 1928, Yvan Goll escribía a Gaston Picard, a quien también había escrito Apollinaire después del estreno de Les Mamelles de Tirésias para aclararle lo que era el superrealismo, con objeto de distinguir entre el superrealismo de Apollinaire y el surrealismo de Breton. BERTHO, Jean, "Autour de la revue Surréalisme", en Surréalisme, no 1, 1924 [edición facsimil: Surréalisme, Paris, Jean-Michel Place, 2004], pp. 23-51, cita p. 48: 
lismo que pretendía hacer visible aquello que la apariencia y la costumbre opacan. Un realismo que, del mismo modo que se conjugan lo visible y lo invisible en el turbio cristal de una radiografía, quería conjugar la realidad convenida con otras desapercibidas o, si se quiere, la posibilidad realizada con la realidad en potencia. En el espacio rizomático de la radiografía se hacía manifiesta esta permeabilidad de las cosas, del espacio y de los cuerpos, de lo conocido y lo ignorado, de lo tenido por real y por ficticio ${ }^{2}$; sencillamente se ponía en movimiento la realidad invisible.

En mayo de 1917, Apollinaire empleaba por primera vez su pertinente neologismo en el programa de Parade. "Ha resultado, en Parade", decía, "una suerte de superrealismo, en el cual veo el punto de partida de una serie de manifestaciones de este espíritu nuevo, que, encontrando hoy la ocasión de mostrarse, no dejará de seducir a la élite y promete modificar a fondo y por completo las artes y las morales en la ligereza universal, pues el buen sentido quiere que estén al menos a la altura de los progresos científicos e industriales"3. Apollinaire consideraba que, si bien tradicionalmente eran los poetas quienes dotaban de mitos a la sociedad, en los últimos años esos momentos inaugurales que recomienzan la historia los estaba brindando la ciencia con descubrimientos e invenciones como los de los rayos-x, la física cuántica, el cine o la aviación; maravillas tecno-científicas que debían ser acicate para la creación artística, para que los artistas volviesen a crear mitologías que desbordasen la realidad y nuestra lógica perceptiva racional. El superrealismo no sería otra cosa que una actitud crítica y dialéctica que observa la realidad, la disloca, la desdice y la dice de vuelta revelando "la magia de la vida cotidiana" $"$.

\footnotetext{
"Ce terme désigne les deux courants les plus caractéristiques, quoique les plus opposés, de notre vie intellectuelle: l'un conduisant vers l'inconscient ou le subconscient, en conformité avec les récentes théories médicales et psychologiques, l'autre, au contraire, vers le superconscient, en écoutant les préceptes de la science, de la technique et de l'art modernes, avec le but suivant: créer, par le truchement de l'œuvre d'art, une réalité surréelle, en extrayant la substance éternelle, le sentiment standard, de la chose quotidienne, de la réalité factice et fugitive, qui, à l'état brut, "photographiée", n'avait conduit qu'au réalisme infécond".

2 La radiografía resulta un rizoma ejemplar, compresión espacial que es tridimensional y bidimensional al mismo tiempo y que anima el rítmico va y ven de superficie y profundidad de las cosas deslizándose una en otra; una de las virtudes que la hicieron atractiva a ojos los artistas que nos ocupan. DELEUZE, Gilles, GUATTARI, Félix, "Introduction: Rhizome", en Mille Plateaux, vol. II: Capitalisme et schizophrénie, Paris, Les Éditions de Minuit, 1980, p. 13: "Le multiple, il faut le faire, non pas en ajoutant toujours une dimension supérieure, mais au contraire le plus simplement, à force de sobriété, au niveau des dimensions dont on dispose, toujours $n-1$ (c'est seulement ainsi que l'un fait partie du multiple, en étant toujours soustrait). Soustraire l'unique de la multiplicité à constituer; écrire à $n-1$. Un tel système pourrait être nommé rhizome".

3 APOLLINAIRE, Guillaume, "Programme de Parade", en Euvres en prose complètes, edición, prefacio y notas de Pierre Caizergues y Michel Décaudin, Paris, Gallimard, vol. II, 1991, pp. 865-867, cita p. 865: "il est résulté, dans Parade, une sorte de sur-réalisme, où je vois le point de départ d'une série de manifestations de cet esprit nouveau, qui, trouvant aujourd'hui l'occasion de se montrer, ne manquera pas de séduire l'élite et se promet de modifier de fond en comble les arts et les mours dans l'allégresse universelle, car le bon sens veut qu'ils soient au moins à la hauteur des progrès scientifiques et industriels".

4 Ibid., p. 867: el espectáculo, decía, “donnera l'essor à leur [del público] libre fantaisie, et tournant la manivelle d'une auto imaginaire [...] exprimera la magie de leur vie quotidienne".
} 
“¿Que no hay nada nuevo bajo el sol?”, exclamaba Apollinaire en su compendio programático El espíritu nuevo y los poetas; "Habrá que verlo. ¡Qué! Me han radiografiado la cabeza. He visto, estando vivo, mi cráneo ¿y eso no será ninguna novedad? ¡A otros con ésas!’5 En efecto, el 17 de marzo de 1916, Apollinaire era herido por la metralla de un obús mientras leía su Mercure de France en una trinchera de los bosques de Buttes, en Berry-au-Bac. Es probable que fuese radiografiado en uno de los vehículos dotados con equipamiento radiológico que Marie Curie había puesto en circulación en colaboración con la Cruz Roja francesa, antes de ser evacuado y trepanado por el Dr. Baudet en el hospital de Auteuil ${ }^{6}$. En los albores del siglo XX, la magia de la electricidad, los rayos-X, el teléfono, el automóvil o el aeroplano, mostraban que, si no hay mucho nuevo bajo el sol, sí al menos mucho por descubrir, y que, dada la contingencia de los conocimientos y la reversibilidad de la realidad, es imperativo replantear continuamente nuestras certezas. Camille Flammarion, uno de los más ilustres exploradores de lo ignoto en la órbita del siglo XX y lectura habitual de muchos niños y no pocos artistas de la época, no contuvo su entusiasmo al tener noticia del descubrimiento de Wilhelm Conrad Röntgen en enero de 1896:

"El descubrimiento reciente de los rayos Röntgen, tan increíble y tan extraño en sí en su origen, debería convencernos de la exigua pequeñez del campo de nuestras observaciones habituales. ¡Ver a través de objetos opacos! ¡En el interior de un cofre cerrado! Distinguir el esqueleto de un brazo, de una pierna, de un cuerpo a través de la carne y de las ropas! Un descubrimiento así contradice todo aquello que considerábamos certezas. Este ejemplo es sin duda uno de los más elocuentes a favor de este axioma: es acientífico afirmar que las realidades se detienen en el límite de nuestros conocimientos y de nuestras observaciones" (fig. 1) ${ }^{7}$.

5 APOLLINAIRE, Guillaume, "L'Esprit nouveau et les poètes" (escrito en 1917, publicado por primera vez en el Mercure de France, vol. CXXX, no 491, 1 de diciembre 1918, pp. 385-396), en Id. (1991), op. cit., pp. 943-954, cita p. 949: “Mais n'y a-t-il de nouveau sous le soleil? Il faudrait voir. Quoi! On a radiographie ma tête. J'ai vu, mon vivant, mon crâne, et cela ne serait en rien de nouveauté? À d'autres!".

6 Las posibles fechas de la trepanación bailan, aunque según Pierre Caizergues habría tenido lugar el 9 de abril. CAIZERGUES, Pierre, "Élements de chronologie", en Cahiers du Musée National d'Art Moderne, $\mathrm{n}^{\circ} 6$ (especial Apollinaire), 1980, pp. 8-9: Después de ser trasladado a l'Hôtel-Dieu de Chateau-Thierr, el 29 Apollinaire era llevado al hospital Val-de-Grace y el 6 de abril al hospital italiano de Quay d'Orsay, donde era trepanado tres días más tarde. El 21 de marzo Apollinaire escribía a Max Jacob contándole lo ocurrido y éste se lo comunicaba a Picasso quien, el 23, escribía a Apollinaire, aunque no acudiría a visitarle a la habitación $\mathrm{n}^{\circ} 13$ del hospital de Val-de-Grâce, como el herido deseaba. Quien sí le visitó a menudo fue Breton, en prácticas en Val-de-Grâce, y con quien hubo de comentar tanto su idea del "espíritu nuevo" como su interés por los lunáticos.

7 FLAMMARION, Camille, L'Inconnu, Paris, Ernest Flammarion, 1900, p. 19: "La découverte récente des rayons Röntgen, si incroyable et si étrange en elle même à son origine, devrait nous éclairer sur l'exiguë petitesse du champ de nos observations habituelles. Voir à travers des objets opaques! Dans l'intérieur d'un coffre fermé! Distinguer le squelette d'un bras, d'une jambe, d'un corps à travers la chair et les vêtements! Une telle découverte est, sans contredit, tout à fait contraire à nos certitudes accoutumées. Cet exemple est assurément l'un des plus éloquents en faveur de cet axiome: il est ascientifique d'affirmer que les réalités s'arrêtent à la limite de nos connaissances et de nos observations". 


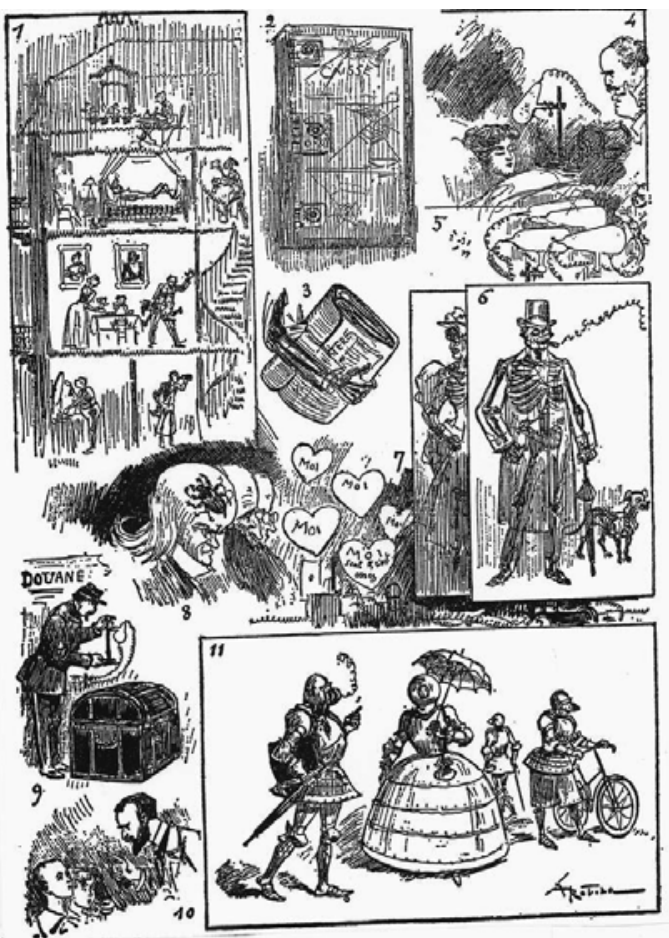

Fig. 1. Albert Robida, Variations sur les rayons $X$, caricatura publicada en La Nature, $\mathrm{n}^{\circ} 1197,9$ de mayo 1896, p. 919: “1) L'indiscrétion des rayons X; 2) Que contient le coffre du banquier?; 3) Que contient la valise du ministre?; 4) A quoi rêve l'amante?; 5) A la recherche de la cachette des microbes; 6) Connais-toi toi-même?; 7) Ce que contient le cour de certains hommes; 8) Ce que contient le cerveau de certains grands savants; 9) Contrôle d'une valise à la douane; 10) Les rayons $X$ vont bien nous montrer qui a mangé le gâteau; 11) La mode de demain pour se protéger de l'indiscrétion de la nouvelle photographie".

realismo mimético. El superrealismo que den
Jugosas palabras las del celebrado astrónomo, que consideraba acientífico afirmar que las realidades, y empleo su pertinente uso del plural, se detienen allí donde alcanzan nuestras percepciones y conocimientos. A partir de la crisis de la realidad aparente precipitada en el último tercio del siglo XIX por las investigaciones en física, matemáticas, filosofía, estética o antropología el conocimiento de la realidad se reveló manifiestamente incierto y contingente, tan movedizo como la belleza y como la historia, que también dejaron de tenerse por únicas y unívocas. En aquel contexto de 1896, cuando también irrumpía en escena el cine, y cuando la aviación y el psicoanálisis comenzaban a abrir nuevos horizontes de visión $y$ de conocimiento, los rayos- $x$ y su huella radiográfica aparecieron como recurso analógico con que mostrar la densidad de la realidad, con que evidenciar la complejidad y el dinamismo de toda realidad, tanto individual como colectiva, contribuyendo de manera decisiva a desmontar el viejo paradigma de mimético. El superrealismo que demandaba aquel modo extraordinario de visión y presentación de la realidad no pretendía otra cosa que serle fiel allí donde el ojo dejaba de serlo, abrirla, desentrañarla y presentar aquello velado por la apariencia o, sencillamente, por la costumbre.

Superrealismo "significa más que realidad, la realidad a ultranza, la vida radiografiada, desnuda hasta los huesos, y toda la carne incendiada: la vida vista con lupa"8. Yvan Goll no pudo ser más claro y preciso: Quererse superrealista sería observar la vida como con rayos-x en los ojos, descarnada y desentrañada profunda y

8 BRASSEUR, Paul, “Chez Ivan Goll”, en Ceux qui viennent, 1925, recogido por BERTHO, Jean (2004), op. cit, pp. 23-51, cita p. 44: "surréalisme signifie plus que la réalité, la réalité à outrance, la vie radiographiée, nue jusqu'aux os, et toute chair incendiée; la vie vue à la loupe". 
levemente, para presentarla en toda su densidad, para hacer visibles sus estructuras y sus ilusiones, para evidenciar que no está hecha más que de esqueletos y fantasmas. Goll supo verlo y, en 1927, publicaba Poemas de la vida y de la muerte ilustrando el frontispicio con una radiografía de su cráneo y del de su esposa Claire9.

Los rayos-x y su huella radiográfica aparecieron como el correlato perfecto de la irrenunciable actitud crítica, dialéctica, irreverente y nunca satisfecha, de la que hablaba Apollinaire, pues, como apuntaba en sus Meditaciones estéticas, "no se descubrirá jamás la realidad de una vez por todas. La verdad será siempre nueva"10. Esta conciencia de que la realidad es siempre otra, no porque su naturaleza sea esencialmente distinta, sino porque es un insustancial entramado de relaciones de fuerzas en renegociación y reconfiguración constante, constituiría el núcleo genético del superrealismo. El superrealismo no se limitaría a apreciar la realidad por lo que es efectivamente real, sino por lo potencialmente real, dado que realidad e irrealidad son anverso y reverso del mismo pliegue. "La Victoria será ante todo/ ver bien de lejos/ ver todo/ de cerca/ y que todo tenga un nombre nuevo", cantaba Apollinaire en $1917^{11}$. La victoria será, como decía el poeta, cuestión de ver, cuestión de no dejar de ver de nuevo y de nuevas las cosas, cuestión de no dejar de cuestionar la realidad, de interpelarla, de desdecirla, de volverla a pensar y a decir. Como habían hecho Alfred Jarry, Raymond Roussel, Alphonse Allais o Charles Cros, y como harían Picasso, Duchamp, Picabia o De Chirico, Apollinaire se esmeró en poner de relieve el carácter dinámico y dialéctico de la realidad, dislocando la visión y el pensamiento. No se trataba de deslocalizar o trasponer el modelo de realidad convencional, sustituyéndolo por otro con parámetros tan alejados de los de aquel como fuese posible, deslizando uno en el lugar del otro, sino de superponer al modelo dado otros tantos posibles. Este modo basculante de ver, digamos, radiológicamente, sólo apto para ojos avezados, es el arte de ver en que aquellos artistas se empeñaron.

Pablo Picasso constituye un ejemplo paradigmático de este arte de ver. En noviembre de 1935, Picasso decía sentir literalmente su epidermis como una placa sensible cubierta de ungüentos hechiceros y albergando una suerte de aparato radiológico en lo más profundo de su interior ${ }^{12}$. Esto es, no sólo decía sentir su dermis como una ex-

9 GOLL, Yvan, Poèmes de la Vie et de la Mort, Paris, Jean Budry, 1927.

10 APOLLINAIRE, Guillaume, Méditations esthétiques (Paris, Figuière, 1913), en Id. (1991), op. cit., pp. 5-52, cita p. 8: “on ne découvrira jamais la réalité une fois pour toutes. La vérité sera toujours nouvelle".

11 APOLLINAIRE, Guillaume, "La Victoire" (Nord-Sud, no 1, 15 de marzo 1917; incluido en Calligrammes, París, Mercure de France, 1918), en Euvres poétiques, edición al cuidado de Marcel Adéma, Michel Décaudin, Paris, Gallimard, 1965, p. 310: "La Victoire avant tout sera/De bien voir au loin/De tout voir/ De près/ Et que tout ait un nom nouveau".

12 PICASSO, Pablo, Écrits, (1935-1959), prefacio de Michel Leiris, Paris, Réunion des Musées Nationaux-Gallimard, 1989, p. 38: “[...] ne radiographiant mon portrait la plaque préparée de cent onguents sorciers m'enveloppant entièrement et l'appareil à l'intérieur au centre le plus profond de mon corps préparé à toutes les surprises les plus désagréables et capable de vous faire mourir de rire du plus grand des bonheurs car dans l'ail du toro tout s'explique par chiffres et rien n'est clair au fond du lac taurin [...]'. Ésta no era la 
traordinaria superficie de registro y receptáculo de emociones, sino contar con un dispositivo de perspicacia superlativa capaz de escrutar lo que late en el interior de los cuerpos y de proyectar sus visiones en el espacio. La joven desnuda que aparece en la esquina de su taller rue Boétie en un fotograbado publicado en el número especial que Cahiers d'Art dedicaba a Picasso en 1937 encarna maravillosamente este modo de concebir de Picasso a base de indigestiones de emociones y descargas de visiones (fig. 2) ${ }^{13}$.

Los rayos-x y la radiografía efectuaban una tarea análoga a la que debía darse el pintor, que es ver en lo invisible y buscar "una semejanza más profunda, más real que lo real, alcanzando lo superreal. Es así como concebía el superrealismo, pero la palabra había sido empleada de modo completamente distinto" ${ }^{14}$. Los rayos-x y la radiografía se revelaron como un estupendo correlato de la práctica artística de quien Apollinaire consideraba capaz de diseccionar los cuerpos con su ojo radioscópico como un

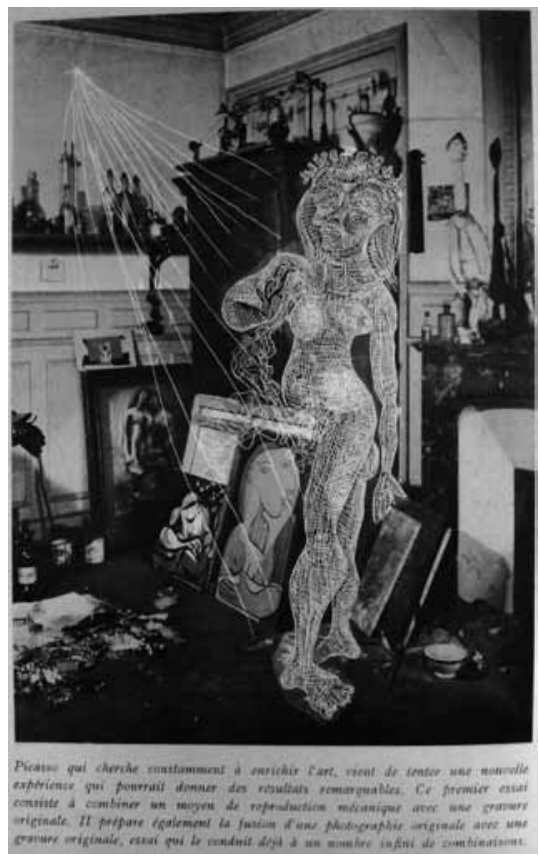

Fig. 2. Pablo Picasso, Nu dans l'atelier, fotograbado, publicado en Cahiers d'Art, vol. XII, nº 6-7, 1937, s.p. [p. 175]. cirujano disecciona un cadáver, un dispositivo que basculaba entre lo mágico y lo científico y que revelaba el cálido espesor de la materia, ese espacio matricial donde Picasso situaba el núcleo genético, menos material que procesual, de las obras de $\operatorname{arte}^{15}$. El vertiginoso bombardeo de fotones de la radiografía desvelaba ese espacio genético y retenía tanto las "visiones primeras"

primera vez que Picasso reflexionaba sobre la capacidad reveladora de los rayos-x. En un cuaderno manejado entre 1917 y 1920 y felizmente recogido en esta compilación de escritos, Picasso anotaba: "Il ne faut/ pas apprendre/ à dessiner/ a t'on mise un/ prisme devant/ la lumière des/ rayons X" (ibid., p. 371).

${ }_{13}$ Cahiers d'Art, vol. XII, no 6-7, 1937, s.p. [p.175]. La fotografía sobre la que Picasso trabaja es de C. Bernès, Marouteau et Cie, "Un coin de l'atelier de Picasso à Paris, janvier 1934", en Cahiers d'Art, vol. X, no 7-10 (número especial Picasso 1930-1935), 1935, s.p. [p. 180]. Brigitte Baer reproducía seis de los múltiples estados del fotograbado, albergados en los archivos del Musée Picasso de París. BAER, Brigitte, Picasso. Peintre-graveur, vol. III (Catalogue raisonné de l'œuvre gravé et des monotypes. 1935-1945), Berne, Kornfeld, 1986, pp. 103-105: 1er estado A (MP 2766); $2^{\circ}$ estado A. a (MP 2767); $2^{\circ}$ estado B. a (MP 2770); $2^{\circ}$ estado B. b (MP 2769); 3er estado A (MP 2771); 3er estado B. a (MP 2772). Es de este último del que se tiraron las pruebas de la ilustración publicada en Cahiers d'Art.

14 BRASSAÏ, Conversations avec Picasso, Paris, Gallimard, 1964, p. 44: "Je cherche à toujours observer la nature. Je tiens à la ressemblance, à une ressemblance plus profonde, plus réelle que le réel, atteignant le surréel. C'est ainsi que je concevais le surréalisme, mais le mot était employé tout autrement...”. Estas declaraciones recogidas por Brassaï se las hacía Picasso a André Warnod en 1945.

15 APOLLINAIRE, Guillaume, "Du sujet dans la peinture moderne", en Les Soirées de Paris, $\mathrm{n}^{\circ}$ 1, 1912, p. 3: "Un Picasso étudie un objet comme un chirurgien dissèque un cadavre". 
que Picasso se lamentaba de perder inevitablemente según veía y pintaba, como los sucesivos estados evolutivos de la obra; esto es, sacaba a la luz todas las realidades, todos los cuadros que se esconden bajo el último cuadro y que no suelen acceder al plano de lo visible.

En los rayos-x y las plaquitas de ombres portées, Marcel Duchamp encontró maravillosamente encarnadas la "metaironía" y el "metarrealismo" que le ocupaban ${ }^{16}$. Unos y otras le ofrecieron una estupenda analogía tanto procesual como formal, de la forma en que quería desnudar, descarnar y desentrañar la realidad y retenerla, incierta y reversible, en una especie de "cristales de tiempo" bergaminescos. Duchamp hizo mención a los rayos-x al menos en dos ocasiones, entre 1914 y 1926, y lo hizo vinculándolos a algunos de los elementos claves para comprender sus reflexiones y su práctica artística: lo infraleve, la transparencia, el corte y la cuarta dimensión, palabras casi mágicas que van combinándose y recombinándose de mil maneras a lo largo de sus notas ${ }^{17}$. Como aquellas enigmáticas plaquitas, los "retrasos en vidrio", o en lo que fuese, de Duchamp no sólo lanzaron un desafío a la pintura y a lo visible, sino que constituyeron uno de los mayores elogios a la realidad, inquieta y reversible, al clinamen universal, diríamos, y una de las más agudas críticas a su representación habitual. Duchamp presentó otras formas de ver y presentar la realidad sin escamotearle ninguna de sus dimensiones formales ni de significado; esto es, comparativamente, no una representación equívocamente realista sino una presentación superrealista de la realidad.

Duchamp estaba en el secreto de los cuerpos y en el secreto aún más profundo de los mecanismos que rigen lo visible. Los desnudamientos duchampianos dejan translucir estructuras biológicas, plásticas y culturales latentes, "visibles o subyacentes", como apuntaba él mismo. De aquí que digamos que los rayos-x constituyeron un recurso revelador de lo invisible tanto formal como procesual; es decir, como registro infraleve en vidrio, así como proceso heurístico de conocimiento.

16 DUCHAMP, Marcel, Duchamp du Signe. Écrits, edición al cuidado de Michel Sanouillet, Paris, Flammarion, 1975, p. 126: "Faire un tableau par ombres portées". Duchamp distinguía su "ironisme d'affirmation" del "ironisme négateur dépendant du Rire seulement" (ibid., p. 46). Como apuntaba Jean-François Lyotard, Duchamp observa las "leyes" -tanto físicas como morales- y, o bien las desmonta y las bricole a su guisa, o bien reinventa otras legislaciones. George Vitoux, autor de uno de los primeros estudios acerca de rayos-x, anticipaba la terminología de Duchamp apuntando que los rayos-x permitían obtener sobre la placa sensible "una imagen representando la sombra portada de los objetos interpuestos" entre el rayo emitido por el tubo de Crookes y la placa. VITOUX, Georges, Les Rayons x et la photographie de l'invisible, Paris, Chamuel, 1896, p. 22: la placa sensible registra "une image représentant l'ombre portée des objets interposés" entre el rayo y ella. Lo fascinante de estas "ombres portées" es que no sólo son sombras, sino huellas y moldes de aquello que han atravesado los rayos-x y que han transformado física y químicamente a su paso.

17 DUCHAMP, Marcel, Notes, edición al cuidado de Paul Matisse, Paris, Centre Georges Pompidou, 1980, n' 23: "Rayons X (?)/Inframince/ Transparence ou coupaison"; n' 189: "le coupant d'une lame et la transparence/ et les Rayons X et la $4^{e}$ Dim." Ambas notas carecen de fecha pero, dado que Duchamp no enunció su idea de distancia infrafina antes de la Primera Guerra Mundial y que una de las notas aparece junto a un boceto para Anémic Cinéma, rodada en 1926, podríamos situarlas dentro de este intervalo temporal. 
Además, las radiografías evidenciaron la reversibilidad de las formas y de los sentidos y la inminencia de los contactos que tenían fascinado a Duchamp. "Ver es tener a distancia". ${ }^{18}$ Esto apuntaba Merleau-Ponty en El ojo y el espiritu, enunciando la esencia de la poética duchampiana y de la técnica radiográfica, una paradigmática "técnica del cuerpo" que "figura y amplifica la estructura metafísica de nuestra carne" y que, como la pintura, "da existencia visible a lo que la visión profana creía invisible" y permite "à-voir la voluminosidad del mundo" 19 . En efecto, la radiografía, de la que podríamos decir que es una especie de fotografía elevada a $n+x$ dimensiones, ofreció a Duchamp un rico campo de experimentación y de reflexión acerca de las cuestiones que, como esos invisibles aflorados o esas diferencias infinitesimales que restan inevitablemente entre los seres, le intrigaban ${ }^{20}$. Una indagación en la génesis de lo visible, una incursión en aquello que late en lo invisible, a la que contribuyeron los rayos-x y las huellas o proyecciones de su paso a través del espacio y de los cuerpos.

Los rayos-x enunciaban la posibilidad de una visión a $n+x$ dimensiones que percibe el espacio como una extensión o profundidad hecha de un sin número de planos infraleves y que se encontraba maravillosamente encarnada en aquellos retrasos en vidrio, estremecidos y carentes de orientación única, desorientados y desorientadores. Esos translúcidos visores portables situados entre Air de Paris y $\grave{A}$ regarder de près, entre molde de aire e instrumento óptico de precisión inverosímil, revelaban que lo visible es una dimensión que se descubre en y desde la profundidad, evidenciaban la reversibilidad de la realidad, o el "principio bisagra" que la articula, y efectuaban la intención de Duchamp de desacreditar todo modelo de representación, plástico o filosófico, y toda convención con pretensión de absoluto. Duchamp, como Alfred Jarry, Alphonse Allais o Albert Robida, quienes también manifestaron en relato o en caricatura su interés por los rayos-X, encontró en los "rayos incógnita" un instrumento de descarga sin par con el cual librar de toda obligación con la memoria o con la historia a la tenida por única y resuelta realidad, aligerándola y presentándola como una posibilidad más entre otras no afloradas.

\footnotetext{
18 MERLEAU-PONTY, Maurice, L'œil et l'esprit, Paris, Gallimard, 1964, cita p. 26: “Voir c'est avoir à distance".

19 Ibid, p. 33: "Toute technique est "technique du corps". Elle figure et amplifie la structure métaphysique de notre chair". "Elle [la pintura] donne existence visible à ce que la vision profane croit invisible" $y$ nos permite "à-voir la voluminosité du monde" (ibid). El acertado juego de palabras que hace Merleau-Ponty conjugando "avoir" y "voir" no es traducible, con lo que es preferible respetarlo en francés.

${ }^{20}$ Duchamp consideraba que un espacio o un cuerpo era igual a la superposición de todos sus espectros; o, lo que es lo mismo, igual a la acumulación compacta de todos los cortes infinitesimales que los conforman. Y ¿qué era una plaquita radiográfica sino el corte infraleve de algún cuerpo, su "imagen a n-1 dimensiones", o su negativo (fotográfico), ese "plano (generador de la forma del objeto por paralelismo elemental)"? DUCHAMP, Marcel (1975), op. cit., pp. 120-122: En “À l'infinitif” (1966), Duchamp hablaba de sombra, huella y molde como "image à n-1dimensions", "négatif (photographique)" y "plan (générateur de la forme de l'objet par parallélisme élémentaire)".
} 
"Todo objeto tiene dos aspectos: uno habitual que vemos casi siempre y que es visto por los hombres en general, y otro que es espectral y metafísico y visto sólo por raros individuos en momentos de clarividencia y abstracción metafísica"21.

Esto decía Giorgio de Chirico en 1919, en su célebre artículo Sobre el arte metafísico. Lo que De Chirico continuaba diciendo, pero rara vez se escucha, es que esos momentos reveladores son como cuando "ciertos cuerpos ocultos formados por materiales que son impenetrables por los rayos solares sólo aparecen bajo el poder de luces artificiales como podrían ser los rayos $X^{\prime 22}$. Los rayos-X y su huella radiográfica anticiparon la clarividencia metafísica de la realidad esencial de las cosas tanto en su forma como en su proceder. En cuanto a su forma, porque, tal como pretendía De Chirico que ocurriese en sus pinturas, en el espesor profundo y translúcido del vidrio se hacía visible lo invisible, el enigma de la cosa, su maravillosa geometría interna, su "íntimo esqueleto", su "espectralidad"; esto es, su realidad metafísica, su sencilla e insensata belleza. Y en cuanto a su proceder, porque en ambas oquedades abiertas a lo invisible quedaban en suspenso la lógica racional y la memoria; los órdenes histórico y estético canónicos desde el Renacimiento quedaban súbitamente desintegrados, esto es, revelaban la esencia ahistórica de las cosas que, a tono con la realidad metafísica de las cosas defendida por De Chirico, podría decirse metahistórica.

Como en radiografía, De Chirico revelaba en pintura lo que late en la "profundidad habitada" de los cuerpos y del espacio. Un ejemplo paradigmático es El doble sueño de primavera (fig. 3), donde De Chirico enmarca una de esas visiones que en ocasiones le sorprendían y le impelían a pintar. En la pintura transparente que centra la composición el espacio, y con él la mirada, se despliega en profundidad más allá del plano pictórico y nos arrastra "ta metà phusikà", revelando aspectos desapercibidos de la realidad. Como en esta paráfrasis espacial, en las plaquitas

${ }^{21}$ De CHIRICO, Giorgio, "Sull'arte metafisica", en Valori Plastici, n’s IV-V, anno I, 1919, pp. 15-18, cita p. 16: "[...] ogni cosa abbia due aspetti: uno corrente quello que vediamo quasi sempre e che vedono gli uomini in generale, l'altro lo spettrale o metafisico che non possono vedere che rari individui in momento di chiaroveggenza e di astrazione metafísica [...]" Existe reproducción anastásica de la revista: Valori Plastici. Rivista d'Arte. 1918-1921, Milán, Gabriele Mazzotta, 1969; la traducción al castellano empleada es la de Jordi Pinós en Sobre el arte metafísico y otros escritos, edición al cuidado de Juan José Lahuerta, Murcia, Colegio Oficial de Aparejadores y Arquitectos Técnicos, no 23, 1990. En su nota introductoria (pp. 9-14), Juan José Lahuerta hace algunas de las apreciaciones más perspicaces y pertinentes acerca de la pintura de Giorgio de Chirico. También sobre De Chirico, ver los dos primeros epígrafes de la primera parte de LAHUERTA, Juan José, 1927: la abstracción necesaria en el arte y la arquitectura de entreguerras, Barcelona, Anthropos, 1989.

22 Ibid., p. 16: "[...] così come certi corpi occultati da materia impenetrabile ai raggi Solari non possono apparire che sotto la potenza di luci artificiali quali sarebbero i raggi X, par esempio". La distinción que hace De Chirico entre luz solar y otras luces artificiales, si bien no es del todo correcta -James Turrel diría que todas son igual de naturales, generadas por la combustión de algo, sea el compuesto de minerales solares, sea el hilo de cobre, o lo que sea- pretende distinguir con claridad entre el modo de ver de los impresionistas y el suyo. Ver los párrafos I y II de los manuscritos de París, sobre "Impressionnisme et sensationnisme”, en De CHIRICO, Giorgio, Il mecanismo del pensiero: critica, polemica, autobiografía. 1911-1943, edición al cuidado de Maurizio Fagiolo dell’Arco, Turín, Giulio Einaudi, 1985, pp. 10-11. 


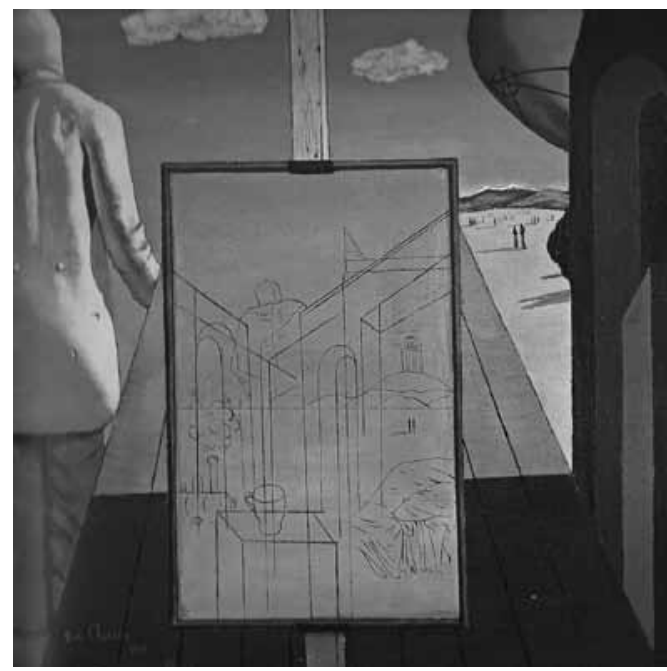

Fig. 3. Giorgio de Chirico, Le double rêve du printemps, enero-mayo 1915, óleo sobre lienzo, 56 x $54 \mathrm{~cm}$., MoMA. radiográficas las cosas se aparecen en enigma. Una y otras son "trampas de espectros" que, como el espejito que el pintor llevaba consigo, descubrían el daimon en cada cosa o, si se quiere, las cosas en calidad de fantasma. Unas y otras serían visores para ver visiones y ser "sorprendidos" por la metafísica de las cosas, por esos otros aspectos de la realidad que la cotidianeidad, la historia y la memoria hurtan a la vista. Unas y otras harían ver al no-metafísico, encarnando esos invisibles y dando ocasión a los momentos cruciales en los cuales se rompe el hilo de la lógica racional y se conjugan pasado y porvenir por un instante. Éste era el propósito de Giorgio de Chirico: hacer que sus pinturas fuesen la ocasión de tornar la ceguera banal en invidencia vidente, o la visión ordinaria en clarividencia metafísica. Esa visión en enigma, esa visión metafísica, esa visión superrealista que, como los kritikshallen de Jules Verne, pone en crisis y critica lo visto, la visión y lo visible, es la que De Chirico descubrió en los rayos-x y la radiografía con sus ojos de clásica astucia ${ }^{23}$.

Francis Picabia encontró en los rayos-x y la radiografía o skiagrafía, esto es, "pintura de sombras" que era otra de las denominaciones que también se le dio, un recurso analógico con el cual explorar las que fueron sus mayores inquietudes desde la infancia: en primer lugar, perder gravedad, tanto en términos de peso como de seriedad; en segundo lugar, extender la visión a todo lo invisible contenido en lo visible; y en tercer lugar afinar, según sus términos, nuestra "métrica interior", haciendo resonar las vibraciones energéticas que tejen la realidad tanto en el artista como en sus obras y en quien las observa. Las conversaciones con Louise Alphonse Davanne, abuelo de Picabia y director de la Sociedad Francesa de Fotografía en

23 Relatando uno de sus Viajes Extraordinarios, Jules Verne, fantástico anticipador de tiempos por ver y explorador incansable de territorios indómitos, hacía referencia a unos "rayos ultra X". A Giorgio de Chirico, como lector entusiasta de las obras de Verne, no le pudo pasar despercibido este relato ni aquellos fantásticos "rayos ultra X", "conocidos bajo el nombre de "kritikshalhen". Estos rayos poseían una fuerza de penetración tan intensa que atravesaban el cuerpo humano y disfrutaban de esta propiedad singular de producir imágenes diferentes, según si el cuerpo atravesado estaba muerto o vivo" VERNE, Jules, "Le Testament d'un Excentrique", en Les Voyages extraordinaires, Paris, Hetzel, 1899, p. 35: "A cette époque, d'ailleurs, on appliquait déjà les rayons ultra X du professeur Friedrich d'Elbing (Prusse) connus sous le nom de "kritikshalhen”. Ces rayons possèdent une force de pénétration si intense qu'ils traversent le corps humain, et jouissent de cette propriété singulière de produire des images différentes, suivant que le corps traversé est mort ou vivant." 
el año y años sucesivos al descubrimiento de Wilhelm Conrad Röntgen en 1895, quien estaba convencido de que la fotografía terminaba con la razón de ser de la pintura, están en el origen de la toma de conciencia de Picabia de que la pintura debía ser registro vibrante de las visiones del artista, susceptible de resonar en cada fibra sensible y sistema colodial de quien la observe. Esa pintura dinamógena, que hace retemblar el protoplasma del observador, sería indudablemente más realista que toda fotografía. De manera que la radiografía sería a la fotografía lo que Picabia pretendía que fuese su pintura a la pretendidamente realista pintura académica. Éste fue el intento valiente y entregado de Picabia por salvar la pintura, por reencantarla, por restituirle su potencia resonante y su poder transformador.

Su pintura, como los Pensamientos sin lenguaje que publicaba en 1919, quería ser, según sus propias palabras, "la radiografía de los rayos mostrando mejor la claridad velada de las cosas" ${ }^{24}$. Picabia quería desvelar tanto los cuerpos como las convenciones sancionadas por camarillas estéticas, institucionales o, sencillamente, por la costumbre. En las radiografías, como quería que ocurriese en sus pinturas, los cuerpos se revelaban claros en su opacidad, aireados, insustanciales; en unas y otras se hacía visible y transitable ese "doble mundo" de sentidos y contrasentidos, sin sentidos únicos, de lógicas y paralogismos. Francis Picabia quiso hacer de sus pinturas invitaciones evocadoras inmarcesibles, tan veloces como el pensamiento y capaces de transportarnos más allá de ellas mismas y de uno mismo; imágenes dialécticas tan potentes como las radiográficas. "No hay ni arte nuevo, ni hombres nuevos", decía Picabia, "sino sencillamente individuos capaces de sentir, de ver visiones, y de expresar lo que otros no supondrían jamás"25. Y ¿qué visión más insospechada que la visión radiológica del espesor aéreo de los cuerpos y del espacio? La radiografía facilitó el intercambio de vistas más insólito y extraordinario. Quien cerca de 1920 formulaba la ecuación no resuelta "whisky + consolador rayos-x", y había pintado en más de una ocasión radiómetros y tubos de Crookes empleados en la generación de rayos-x (fig. 4), compartía la aguda apreciación de Albert Cozanet de que "vivir es vibrar", generar desequilibrios y "cacodilatar" los ojos, o, dicho de otro modo, es estremecerse sencillamente ${ }^{26}$.

24 PICABIA, Francis, Pensées sans langage, Paris, Eugène Figuière, 1919, s.p. [p. 9]: “Ce livre est la radiographie des rayons montrant le mieux la netteté voilée des substances qu'exige l'aiguille fermée". Inmediatamente antes, Picabia hablaba confusamente de tubos con "atmósferas rarificadas al extremo", "bobinas", "condensadores" y demás aparataje propio de experiencias con rayos-x.

25 PICABIA, Francis, "Le génie et le fox-terrier" (Comoedia, 16 de mayo 1922, p. 1), en Écrits critiques, edición al cuidado de Carole Boulbès, prefacio de Bernard Noël, Paris, Mémoire du Livre, 2005, pp. 126-129, cita p. 126: "il n'y a ni art nouveau, ni hommes nouveaux, mais simplement des hommes ayant le don de sentir, puis d'exprimer, ce que les autres ne supçonneront jamais dans la vie ambiante. Ces hommes à antennes nous inquiètent et nous attirent, c'est parmi eux qu'on peut découvrir le génie".

26 UDINE, Jean d' [Albert Cozanet], L'Art et le geste, París, Félix Alcan, 1910, p. 3: "Vivre c'est vibrer". En una especie de poema titulado Dada-Madrid que, si bien no está fechado, es posible datar entre 1919 y 1924, momentos de encuentro y desencuentro con el grupo de Tristan Tzara, escribía "Whisky + consolador rayos-x". PICABIA, Francis, "Dada-Madrid", en Id. (2005), op.cit., pp. 621-622, cita p. 622: "Whisky + 
“¿Quién puede creer aún en la opacidad de los cuerpos?"27. Esto se preguntaban los pintores futuristas en su manifiesto técnico de pintura en 1910. ¿Quién puede creer aún en ella, cuando nuestra multiplicada sensibilidad y nuestra agudeza visual pueden dar resultados análogos a los de los rayos$\mathrm{x}$ ?, decían. Los futuristas fueron los primeros y los únicos que, en tanto que grupo, oficializaron su admiración por el descubrimiento, arrogándose la capacidad de ver "como con rayos-X". Esa visión radiológica de la que hablaban los futuristas descubriría las cosas, los cuerpos y el espacio en que se inscriben como una profundidad abierta, "unánime" y dinámica. En el turbio cristal de las plaquitas radiográficas se había hecho visible aquella nueva sensibilidad, de la cual los italianos decían ser los primitivos, que descubría las resonancias de todo

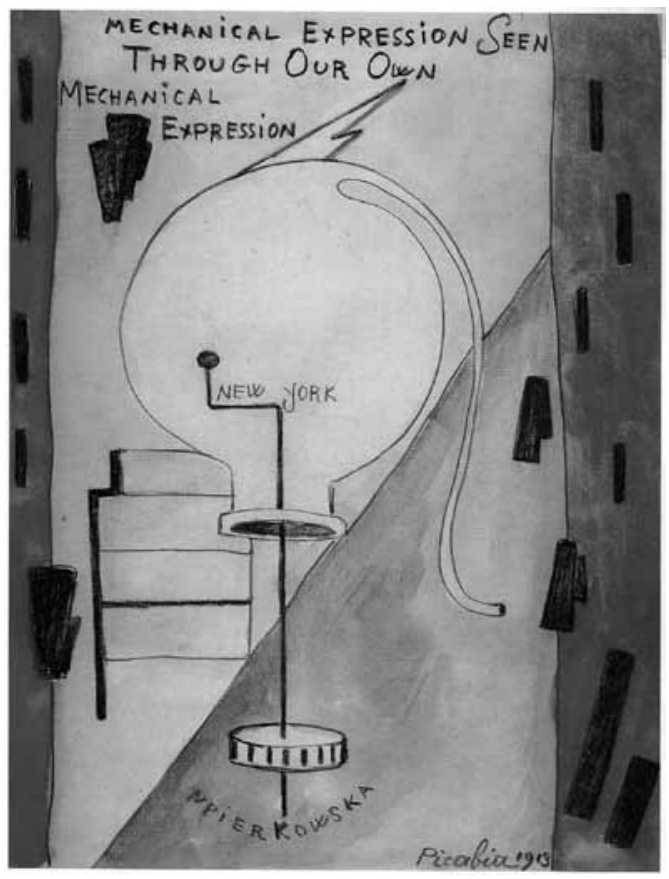

Fig. 4. Francis Picabia, Mechanical expression seen through our own mechanical expression, 1913, acuarela y lápiz sobre papel, 19,7 x $16 \mathrm{~cm}$., colección particular. en todo, liquidando con ello la otrora incuestionable y preciosista delimitación de los cuerpos. Boccioni formuló aquel dinamismo, fundamentalmente coincidente con las tesis de Henri Bergson, como la suma del movimiento absoluto y del movimiento relativo de los cuerpos; o, dicho con otras palabras, la síntesis plástica de la evolución creadora enunciada por Bergson donde se conjugaban el movimiento de los cuerpos observados "desde fuera" y el estremecimiento de los mismos observados "desde dentro" 28 . Como en una

Godemiché rayons X'. Este texto, conservado en los fondos Tzara de la Bibliothèque Jaques Doucet con la signatura TZR C 3043, fue publicado por primera vez en PICABIA, Francis, Écrits, vol. I, edición al cuidado de Olivier Revault d'Allonnes y Dominique Bouissou, París, Belfond, 2, 1975, p. 268.

27 BOCCIONI, Umberto, CARRÀ, Carlo, RUSSOLO, Luigi, BALLA, Giacomo, SEVERINI, Gino, La Pittura Futurista. Manifesto Tecnico, Direzione del Movimento Futurista, Milán, 11 de abril 1910, en CARUSO, Luciano, Manifesti, proclami, interventi e documenti teorici del Futurismo: 1909 - 1944, Florencia, Spes, 1980, caja 1 (1909-1917: documentos no s 1-112), s.p. [p. 1 del documento]: "Chi può credere ancora all'opacità dei corpi, mentre la nostra acuita e moltiplicata sensibilità ci fa intuire le oscure manifestazioni dei fenomeni medianici? Perchè si debe continuare a creare senza tener conto della nostra potenza visiva che pouò dare risultati analogi a quelli dei raggi X?". Todos los documentos futuristas citados están reproducidos en esta compilación.

${ }_{28}$ BOCCIONI, Umberto, "Absolute Motion + Relative Motion = Dynamism”, en Lacerba, 15 de marzo 1914 
plaquita radiográfica, el dinamismo de los cuerpos debía hacerse visible despojándolos de su materialidad hasta tornar inciertos sus perfiles rigurosos y dejar translucir en su epidermis los múltiples planos del ambiente en que se inscriben y del que forman parte constitutiva. Con mayor o menor fortuna, las pinturas y esculturas futuristas quisieron abrir pasajes radiológicos "entre el infinito plástico exterior y el infinito plástico interior"29; quisieron "dar esqueleto y carne a lo invisible, a lo impalpable, a lo imponderable, a lo imperceptible" $" 30$.

Tres años después que los futuristas, fueron los rayonistas rusos quienes, en su manifiesto de pintura, hicieron referencia a los rayos-x al exponer su "doctrina de la luminosidad". ${ }^{31}$ Los Rayonistas, como los Futuristas y los Vorticistas, consideraban el universo como un entramado de radiaciones electromagnéticas de las que la pintura debía ser superficie de registro y catalizador. Es decir, que aquella miríada de radiaciones electromagnéticas no sólo quedaría recogida en las obras de arte, sino que éstas a su vez irradiarían, dejando su huella fosfénica impresa en la retina de quien las observase. La buena pintura, no necesaria ni exclusivamente la de estos rusos, italianos y británicos, sino la buena pintura en general, reverbera e impresiona, literalmente.

No obstante, donde mejor se encarnó la evolución creadora de Bergson, el dinamismo de los futuristas o la doctrina de la luminosidad rayonista no fue en pintura, ni en escultura, sino en danza; y más concretamente en las danzas de la fée électricité. Thomas Alba Edison y los Curie fueron quienes introdujeron a Loïe Fuller en el mundo de los rayos-x y de la radioactividad, respectivamente ${ }^{32}$. En sus danzas luminiscentes, elo-

29 BOCCIONI, Umberto, Manifesto Tecnico della scultura futurista, Direzione del Movimento Futurista, Milán, 11 abril 1912, s. p.: "Conclusioni 9: "La cosa che si crea non è che il ponte tra l’infinito plastico esteriore e l'infinito plastico interiore",".

30 BALLA, Giacomo, DEPERO, Fortunato, Ricostruzione Futurista dell'Universo, Direzione del Movimento Futurista, Milán, 11 de marzo 1915, s.p.: "Noi futuristi, Balla e Depero, vogliamo realizzare questa fusione totale per ricostruire l'universo rallegrandolo, cioè ricreandolo integralmente. Daremo scheletro e carne all 'invisibile, all 'impalpabile, all 'imponderabile, all 'impercettibile".

31 LARIONOV, Mikhail, Pintura Rayonista (Luchistskaya zhivopis, Moscú, junio 1913), en BOWLT, John E., Russian Art of the Avant Garde: Theory and Criticism, 1902-1934, Nueva Cork, Viking Press, 1976, pp. 91-100, cita p. 98: "en términos puramente oficiales, el rayonismo procede de los siguientes principios: $L a$ luminosidad debe su existencia a la luz reflejada (entre objetos en el espacio esto forma una especie de polvo coloreado) / La doctrina de la luminosidad. / Rayos radioactivos. Rayos Ultravioleta. Reflectividad"

32 En un manuscrito inédito titulado Conferencia sobre el Radium, fechado en 1911, Loïe Fuller recordaba cómo su entusiasmo por la radioactividad había surgido en el laboratorio neoyorkino de Thomas Alba Edison en 1896. FULLER, Loïe, Lecture on Radium (1911), en Notebooks and letters, 1907-1911 (1 caja que contiene esencialmente dos cuadernos, Lecture on Radium y Prelude to Light, digitalización del manuscrito inédito disponible en la New York Public Library of the Performing Arts, signatura NYPY99-A0), pp. 1A-19A, cita pp. 2A-3A: "Mr.Edison took me into a dark room where he showed me the X ray./ For the benefit of those few who have not seen it, I will explain what the thing that I saw looked like./ It was a little box with a handle underneath-just like that in which we see stereoscopic views, only there was a top on it, so that it was all enclosed. I at once wanted to know what was inside of this box, well inside of it instead of a picture, there was a wall of something white that looked as if table salt had been pasted over it./ Outside of the box-held just back of it-was a tiny electrical sort of green lamp, at least the light in the bulb was green./Until this light 
giadas por Valéry, se hacía evidente el devenir de las formas, los pliegues y repliegues de la realidad. La Loïe, "reveladora inconsciente" a decir de Mallarmé, se desprendía y volvía a prenderse de los metros de organdís y muselinas que, como epidermis finísimas, descubrían y cubrían su cuerpo, mostrándola siendo continuamente otra. Loïe Fuller, iniciada en los misterios de la luz y entusiasta de todo descubrimiento científico revelador de lo invisible que late bajo la dermis de las cosas o simplemente queda fuera del alcance de la vista, brindaba esas ocasiones extraordinarias en las que uno se sumerge en el dinamismo de la realidad, "cierra los ojos y baila" como decía Picasso. El 1 de julio aparecía publicada en Lacerba la primera tentativa de letteratura-pittura de Severini, aunque su Bailarina = mar había sido rebautizada sin previo aviso como Danza Serpentina (fig. 5). No obstante, y en defensa de Marinetti, a quien Severini

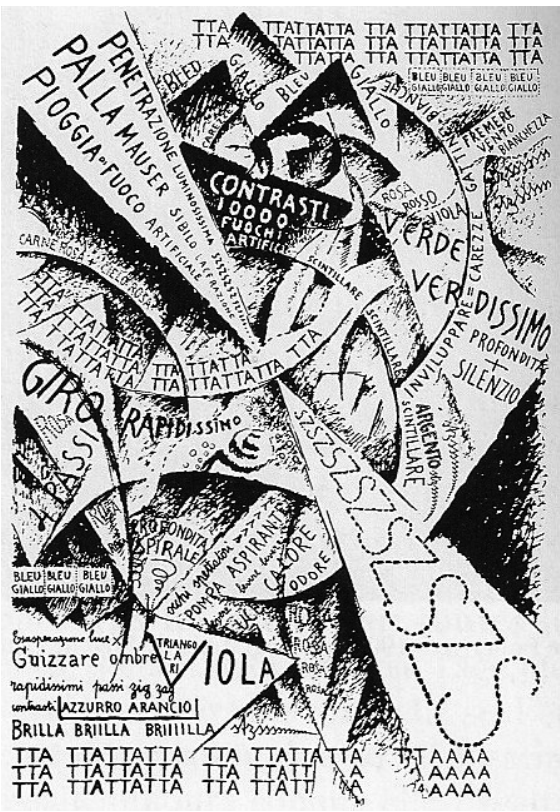

Fig. 5. Gino Severini, Danza serpentina, publicado en Lacerba, vol. II, nº 13, 1 de julio 1914, p. 202. acusó probablemente con razón del cambiazo, este "ideograma futurista" de una bailarina hecha de onomatopeyas de intenso valor plástico, sonoro y analógico, conducía indudablemente a intuir las danzas eléctricas, vibrantes y centelleantes de La Loïe, flotando sobre las luces proyectadas bajo los suelos de vidrio ideados por ella, girando iluminada en derredor por focos eléctricos con filtros de colores, desplegando y replegando aquellos vestidos vaporosos e interminables sobre los que proyectaba imágenes tomadas al microscopio y con rayos-x o que brillaban verdosos teñidos con soluciones de radio ${ }^{33}$.

El conjunto de estas incursiones en el arte de comienzos del siglo XX a la luz de los rayos-x han ido poniendo de manifiesto, en primer lugar, la crítica denodada de estos artistas al realismo mimético canónico, en segundo lugar, su exigencia de un realismo más profundo y dinámico que aquél y, en ter-

was turned on all appeared to be dark inside the box./Then Mr.Edison explained to me that the wall in the box was covered with phosphorescent salts which absorbed light as sand does water, and they became luminous./ This curious light held me spellbound".

${ }^{33}$ BOHN, Willard, "Gino Severini and Futurist Ideography: Danzatrice = Mare", en MLN, vol. CIX, $\mathrm{n}^{\circ}$ 1, enero 1994, pp. 27-48. Bohn argumenta que lo que Severini presentaba eran faros, una hélice de aeroplano y la bala silbando de un Mauser, un rifle alemán muy apreciado por su precisión. En efecto, Severini escribía "PALLA MAUSER SIBILO LACERAZIONE", "BALA MAUSER LACERACIÓN SILBANTE”, pero ¿por qué desechar una analogía de la danza en beneficio de una analogía bélica y empobrecer la capacidad evocadora y dialéctica del "tentativo di letteratura pittura" de Severini? Por otro lado, Severini también apuntaba "Exasperazione luce X", "PROFONDITA SPIRALE", “VERDE VERDISSIMO", "PENETRAZIONE LUMINOSISSIMA SZSZSZSZS", en términos que sugieren otra analogía: la analogía radiológica. 
cer lugar, que los rayos-x y la huella de su paso a través de los cuerpos les brindaron una analogía procesual y formal idónea de ese modo de ver y presentar la realidad en profundidad, desplegando inagotablemente nuevos horizontes de visión y de conocimiento, en la que se empeñaron con fruición. La hipótesis de trabajo con la que se comenzó esta investigación, esto es, observar las posibles resonancias de uno de los descubrimientos científicos más revolucionarios de la época en la práctica artística coetánea, se fue viendo confirmada más allá de las expectativas a lo largo de la misma. De forma que las resonancias que andábamos buscando no sólo fueron haciéndose evidentes en pinturas y escritos, sino que aparecieron jugando un papel inesperadamente relevante en el arte del primer tercio del siglo XX. Y, además, permiten enunciar la tesis de que, más allá de los matices propios de toda subjetividad, la inquietud más urgente de aquellos artistas era ser superrealista. 